\title{
Lack of evidence for mutations or deletions in the CDKN2A/p16 and CDKN2B/p15 genes of Brazilian neuroblastoma patients
}

C.L. Bassi ${ }^{1}$, L. Martelli ${ }^{1}$,

R. Cipolotti², C.A. Scrideli ${ }^{2}$, R. Defávery ${ }^{2}$ and L.G. Tone ${ }^{2}$
Departamentos de ${ }^{1}$ Genética, and ${ }^{2}$ Pediatria e Puericultura, Faculdade de Medicina de Ribeirão Preto, Universidade de São Paulo, Ribeirão Preto, SP, Brasil

\author{
Correspondence \\ L.G. Tone \\ Departamento de Pediatria e \\ Puericultura \\ HC, FMRP, USP \\ Av. Bandeirantes, 3900, 7o andar \\ 14048-900 Ribeirão Preto, SP \\ Brasil \\ E-mail: Igtone@fmrp.usp.br
}

Publication supported by FAPESP. $\ldots \ldots \ldots \ldots \ldots \ldots$

Received August 13, 2003 Accepted July 21, 2004

\begin{abstract}
Neuroblastoma, the most common extracranial tumor in childhood, has a wide spectrum of clinical and biological features. The loss of heterozygosity within the 9p21 region has been reported as a prognostic factor. Two tumor suppressor genes located in this region, the $\mathrm{CDKN} 2 \mathrm{~B} / p 15$ and $\mathrm{CDKN} 2 \mathrm{~A} / p 16$ (cyclin-dependent kinase inhibitors $2 \mathrm{~B}$ and $2 \mathrm{~A}$, respectively) genes, play a critical role in cell cycle progression and are considered to be targets for tumor inactivation. We analyzed $\mathrm{CDKN} 2 \mathrm{~B} / p 15$ and $\mathrm{CDKN} 2 \mathrm{~A} / p 16$ gene alterations in 11 patients, who ranged in age from 4 months to 13 years (male/female ratio was 1.2:1). The most frequent stage of the tumor was stage IV $(50 \%)$, followed by stages II and III $(20 \%)$ and stage I $(10 \%)$. The samples were submitted to the multiplex PCR technique for homozygous deletion analysis and to single-strand conformation polymorphism and nucleotide sequencing for mutation analysis. All exons of both genes were analyzed, but no deletion was detected. One sample exhibited shift mobility specific for exon 2 in the CDKN2B/p 15 gene, not confirmed by DNA sequencing. Homozygous deletions and mutations are not involved in the inactivation mechanism of the CDKN2B/ $p 15$ and $\mathrm{CDKN} 2 \mathrm{~A} / p 16$ genes in neuroblastoma; however, these two abnormalities do not exclude other inactivation pathways. Recent evidence has shown that the expression of these genes is altered in this disease. Therefore, other mechanisms of inactivation, such as methylation of promoter region and unproperly function of proteins, may be considered in order to estimate the real contribution of these genes to neuroblastoma genesis or disease progression.
\end{abstract}

Neuroblastoma originates in pluripotential cells derived from the neural crest and is the most common childhood solid extracranial neoplasm with a world incidence of approximately 8.0 /million per year in chil-
Key words

- p15 gene

- p16 gene

- Deletion

- Mutation

- Neuroblastoma

$\ldots \ldots \ldots \ldots \ldots \ldots \ldots$ dren under 15 years of age and of 7.3/million in Brazil $(1,2)$.

MYCN/N-myc amplification is one of the most important prognostic factors among the genetic events which occur in neuroblas- 
toma. However, some cases of advanced disease were described without MYCN/Nmyc amplification, indicating that other genetic events are also responsible for neuroblastoma evolution. Takita et al. (3) reported that the loss of heterozygosity of the short arm of chromosome $9(9 p)$ is associated with the advanced stage and a poor prognosis, regardless of MYCN/N-myc amplification. Two tumor suppressor genes, CDKN2B/p15 and CDKN2A/p16 (cyclin-dependent kinase inhibitors $2 \mathrm{~B}$ and $2 \mathrm{~A}$, respectively), are located in the 9p21 region and can be targets of inactivation in cases with heterozygosity loss in this region $(4,5)$. Both are cyclin-dependent kinase inhibitors and, once these genes are inactivated, the cells become free of the restrictions imposed by them and uncontrolled cell reproduction can occur.

In the present investigation we have searched for deletion and/or mutation of the $\mathrm{CDKN} 2 \mathrm{~B} / p 15$ and $\mathrm{CDKN} 2 \mathrm{~A} / p 16$ genes in neuroblastomas in an attempt to correlate gene alterations with the origin and progression of the tumor.

We analyzed tumor samples from 11 patients attended at the Pediatric Oncology Unit of the University Hospital, School of Medicine of Ribeirão Preto, University of São Paulo, from 1988 to 1997. Neuroblas-

Table 1. Clinical pathological data and outcome of patients with neuroblastomas.

\begin{tabular}{ccccccc}
\hline Patient & Sex & Age & Diagnosis & Primary site of tumor & Stage & Outcome \\
\hline 1 & M & 2 years & NB & Retroperitoneal & III & Alive \\
2 & M & 7 years & NB & Retroperitoneal & IV & Dead \\
3 & F & 4 months & NB & Paravertebral & I & Alive \\
4 & M & 1.5 years & NB & Abdominal & IV & Dead \\
5 & M & 2.5 years & NB & Suprarenal & III & Dead \\
6 & F & 11 years & NB & Extramedullary & II & Dead \\
7 & M & 13 years & GNB & Abdominal & II & Dead \\
8 & F & 2.5 years & NB & Retroperitoneal & IV & WF \\
9 & M & 1 year & NB & Posterior mediastinum & ND & WF \\
10 & F & 6 years & NB & Adrenal & IV & Alive \\
11 & F & 8 months & NB & ND & IV & Alive \\
\hline
\end{tabular}

The tumors were staged according to the International Neuroblastoma Staging System (INSS; Ref. 6). $M=$ male; $F=$ female; $N B=$ neuroblastoma; $G N B=$ ganglioneuroblastoma; $\mathrm{WF}=$ without follow-up; $\mathrm{ND}=$ not determined toma diagnosis was confirmed by histopathology. The study was approved by the Ethics in Research Committee, process HCRP No. 2865/99, and the persons responsible for the patients gave written informed consent to participate. Clinical and pathological data and patient outcome are listed in Table 1 . The patients ranged in age from 4 months to 13 years (median $=5$ years) and the male/female ratio was $1.2: 1$. Ten patients were classified according to the International Neuroblastoma Staging System (INSS; Ref. 6): the tumor was defined as stage I in 1 patient $(10 \%)$, as stage II in 2 patients $(20 \%)$, as stage III in 2 patients (20\%), and as stage IV in 5 patients $(50 \%)$. Four patients are still alive, 5 patients died because of failure to achieve complete remission or relapse and the outcome is unknown for 2 patients who were lost to follow-up.

The multiplex PCR technique was used to detect deletions in the exons of the genes (CDKN2B/p15 and CDKN2A/p16 consist of 2 and 3 exons, respectively, all of which were studied in the present investigation). We used specific primers for each exon, which were simultaneously amplified with the $\beta$-globin gene as an internal control. The PCR product was then applied to $2 \%$ agarose gel and the electrophoretic run was performed with Tris/borate EDTA (TBE, $0.089 \mathrm{M}$ Tris, $0.089 \mathrm{M}$ borate, $2 \mathrm{mM}$ EDTA) buffer $1 \mathrm{X}$ at $80 \mathrm{~V}$, for approximately $30 \mathrm{~min}$. The samples were prepared using the PCR product, $0.001 \%$ SDS/EDTA and staining solution. The samples were then denatured at $94^{\circ} \mathrm{C}$ for 10 min, placed on ice and applied to $6 \%$ acrylamide gel. Electrophoresis was performed with TBE buffer $1 \mathrm{X}$ at $200 \mathrm{~V}, 40 \mathrm{~mA}$ and $8 \mathrm{~W}$ for 4.5 to $6.0 \mathrm{~h}$. The gel was stained with silver, developed with a sodium carbonate solution, fixed in $10 \%$ acetic acid and dried on transparent paper. The PCR products exhibiting abnormally migrating bands were submitted to manual sequencing reactions with the $\mathrm{T} 7$ sequencing kit $^{\mathrm{TM}}$ (Amersham Pharmacia Biotech, Uppsala, Sweden) 
according to manufacturer recommendations and labeling was performed with the $\left[\alpha^{35} \mathrm{~S}\right]$ dATP radioisotope. The samples were submitted to electrophoresis on $6 \%$ polyacrylamide denaturing gel, transferred to Whatman filter paper, vacuum dried, and exposed in a cassette to X-ray film for 5 to 7 days.

The frequency of genetic alterations of the $\mathrm{CDKN} 2 \mathrm{~B} / p 15$ and $\mathrm{CDKN} 2 \mathrm{~A} / p 16$ genes is extremely variable in acute lymphoblastic leukemia, the most common cancer in children, according to the origin of the patients studied (7-9). Few studies have investigated the mutation involving deletion in these genes in neuroblastomas $(3,10-13)$.

In the present study, no deletion was detected in any exon of the CDKN2B/p15 and CDKN2A/p16 genes. Single-strand conformation polymorphism analysis allowed the screening of the samples to be sequenced. Only one showed a different migration for exon 2 of gene $\mathrm{CDKN} 2 \mathrm{~B} / p 15$, but no alteration was detected in the base sequence of the exon by nucleotide sequencing. Thus, no mutation or deletion was detected in any of the analyzed exons.

According to studies carried out on neoplasms and cell lines, deletion of the $\mathrm{CDKN} 2 \mathrm{~A} / p 16$ gene is a rarely detected event in neuroblastomas, regardless of the technique used (10-13). There is only one report of deletion in a cell line described by Easton et al. (14). Our results suggest that deletion is not an important mechanism of CDKN2A/ p16 gene inactivation in neuroblastomas. Few mutations in the CDKN2A/p16 gene have been described in neuroblastomas, either in neoplasms or in cell lines, and most represent polymorphisms or substitutions that do not affect the protein structure $(10-12,15)$. The only significant alteration was a nonsense mutation in codon 52 described by Takita et al. (3).

The CDKN2B/p15 gene has not been extensively investigated up to now for deletion and mutation in neuroblastomas, and no alteration was detected in the available stud- ies (12). Our results corroborate the findings of Iolascon et al. (12). It has been suggested that deletion and mutation are not the mechanisms of $\mathrm{CDKN} 2 \mathrm{~B} / p 15$ inactivation in neuroblastomas. However, the number of studies carried out does not permit any conclusions.

Although no changes were detected in these genes, it should be kept in mind that deletion and mutation are not the only gene inactivation mechanisms. Transcription inactivation of the CDKN2B/p15 and CDKN2A/ p16 genes associated with hypermethylation of the $\mathrm{CpG}$ islands (areas of increased density of the dinucleotide sequence cytosinephosphate diester-guanine) have been described in several neoplasms $(16,17)$. Inactivation of the $\mathrm{CDKN} 2 \mathrm{~A} / p 16$ gene has even been found in cancers in which homozygotic deletion is rare (18) indicating that this gene may be inactivated much more frequently in human neoplasms than detected in deletion studies. Methylation of the promoter region of the $\mathrm{CDKN} 2 \mathrm{~A} / p 16$ gene has been detected in neuroblastoma cell lines and tumors, associated or not with the absence of gene expression $(3,12,17)$. The possible role of methylation in the inactivation of the $\mathrm{CDKN} 2 \mathrm{~B} / p 15$ gene in neuroblastomas has not yet been investigated.

Another inactivation mechanism which should be considered is the interaction of proteins coded by these genes with a regulator protein, which could block the action of cyclin-dependent kinase inhibitors. Some studies have reported progression of the cell cycle in neuroblastomas even in the presence of high Cdkn2b/p15 and Cdkn2a/p16 expression levels, suggesting a mechanism that does not interfere with gene expression, but interferes with protein activity $(12,14,16)$. Easton et al. (14) suggested that a complex of the Cdkn2a/p16 protein with another regulator protein may explain these data, since there is evidence that the $\mathrm{Cdkn} 2 \mathrm{a} / \mathrm{p} 16$ protein product, and perhaps also the Cdkn2b/ p15 protein product, can be inactivated by interaction with the oncoprotein Tax of the 
leukemia human type 1 virus. Interestingly, Omura-Minamisawa et al. (19) reported that neuroblastomas in unfavorable stages exhibit expression of Cdkn2a/p16 mRNA and protein more frequently than those in the favorable stages, and were significantly associated with a lower overall survival. Cdkn2a/p16 protein expression did not correlate with the phosphorylation status of $\mathrm{pRb}$, and these investigators suggested that Cdkn2a/p16 protein may not be functioning properly to regulate the Cdk4-6/cyclin D/ $\mathrm{pRb}$ pathway. Therefore, the absence of gene alterations in our samples may indicate that the CDKN2A/p16 gene is really intact and expressing itself, and its action could be blocked by some pathway, leading to a poor prognosis in the great majority of patients. The CDKN2B/p15 and CDKN2A/p16 genes are important for cell cycle control and consequently are considered to be the preferred target for inactivation in tumors that, like neuroblastomas, commonly present loss of heterozygosity in 9p21. However, it has been demonstrated that the loss of heterozygosity can involve neighboring regions of the $\mathrm{CDKN} 2 \mathrm{~B} / p 15$ and $\mathrm{CDKN} 2 \mathrm{~A} / p 16$ genes, suggesting the presence of another tumor suppressor gene in this region. Giordani et al. (20) have identified two regions of frequent allelic loss in neuroblastomas, which appear to be distant from the CDKN2B/p15 and $\mathrm{CDKN} 2 \mathrm{~A} / p 16$ genes, suggesting that other genes may be involved in $9 p$ deletion. It has been recently reported that, besides abnormal expression of the CDKN2A/p16 gene, alterations in the expression of $\mathrm{p} 14 /$ $\mathrm{ARF}$ (but not of the CDKN2B/p15 gene) are associated with a poor prognosis in neuroblastomas, suggesting that p14/ARF, identified in the same region of the CDKN2B/p15 and $\mathrm{CDKN} 2 \mathrm{~A} / p 16$ genes in $9 \mathrm{p} 21$, can contribute to tumorigenesis in this disease (21).

To conclude, our results is in agreement with previous reports, which demonstrated that homozygous deletion and mutation are not preferential mechanisms of inactivation of $\mathrm{CDKN} 2 \mathrm{~B} / p 15$ and $\mathrm{CDKN} 2 \mathrm{~A} / p 16$ genes in neuroblastoma.

\section{Acknowledgments}

We thank the surgeons of the Department of Surgery, Orthopedics and Traumatology, FMRP, USP, who made possible the collection of the samples used in this study. Thanks are also due to Dr. Lucila Leico Kagohara Elias and to Simone Kashima for providing part of the material for nucleotide sequencing, and to Lucia Helena G. Teixeira for technical support.

\section{References}

1. Castleberry RP (1997). Biology and treatment of neuroblastoma. Pediatric Clinics of North America, 44: 919-937.

2. Hospital do Câncer A.C. Camargo. Registro Hospitalar do Câncer Pediátrico - 1988 \& 1994 (1999). Monografias do Registro Hospitalar do Câncer. Centro de Tratamento e Pesquisa do Hospital do Câncer A.C. Camargo, São Paulo, SP, Brazil.

3. Takita J, Hayashi Y, Kohno T, Yamaguchi N, Hanada R, Yamamoto K \& Yokota J (1997). Deletion map of chromosome 9 and p16 (CDKN2A) gene alterations in neuroblastoma. Cancer Research, 57: 907-912.

4. Hannon GJ \& Beach D (1994). p15 INK4B is a potential effector of TGFß-induced cell cycle arrest. Nature, 371: 257-261.

5. Serrano M, Hannon J \& Beach D (1993). A new regulatory motif in cell-cycle control causing specific inhibition of cyclin D/CDK4. Nature, 366: 704-707.

6. Brodeur GM, Seeger RC, Barrett A et al. (1988). International criteria for diagnosis, staging, and response to treatment in patients with neuroblastoma. Journal of Clinical Oncology, 6: 1874-1881.

7. Maloney KW, McGavran L, Odom LF \& Hunger SP (1998). Diferent patterns of homozygous $p 16^{\text {INK4A }}$ and p1 $15^{\text {INK4B }}$ deletions in childhood acute lymphoblastic leukemias containing distinct EA2 translocations. Leukemia, 12: 1417-1421.

8. Lemos JAR, Defavery R, Scrideli CA \& Tone LG (1999). Alterations of the p16 gene in Brazilian children with acute lymphoblastic leukemia. Medical and Pediatric Oncology, 33: 223 (Abstract).

9. Cipollotti R, Lemos JAR, Bassi CL, Scrideli CA, Defavery R \& Tone LG (1999). p15 INK4B/MTS2 in Brazilian children with acute lymphoblastic leukemia (ALL). Medical and Pediatric Oncology, 33: 268 (Abstract)

10. Beltinger CP, White PS, Sulman EP, Maris JM \& Brodeur GM (1995). No CDKN2 mutations in neuroblastomas. Cancer Research, 55: 2053-2055. 
11. Castresana JS, Gomez L, Garcia-Miguel P, Queizan A \& Pestana A (1997). Mutational analysis of the p16 gene in human neuroblastomas. Molecular Carcinogenesis, 18: 129-133.

12. Iolascon A, Giordan L, Moretti A, Tonini GP, LoCunsolo C, Mastropietro S, Borrielo A \& Ragione FD (1998). Structural and functional analysis of cyclin-dependent kinase inhibitor genes (CDKN2A, CDKN2B and CDKN2C) in neuroblastoma. Pediatric Research, 43: 139-144

13. Takita J, Hayashi Y, Kohno T, Shiseiki M, Yamaguchi N, Hanada R, Yamamoto K \& Yokota J (1995). Allelotype of neuroblastoma. Oncogene, 11: 1829-1834.

14. Easton J, Wei T, Lahti JM \& Kidd VJ (1998). Disruption of the cyclin D/cyclin-dependent kinase/INK4/retinoblastoma protein regulatory pathway in human neuroblastoma. Cancer Research, 58: 26242632.

15. Diccianni MB, Omura-Minamisawa M, Batova A, Le T, Bridgeman $L$ \& Yu AL (1999). Frequent deregulation of the $p 16$ and the $p 16 / \mathrm{G}_{1}$ cell cycle-regulatory pathway in neuroblastoma. International Journal of Cancer, 80: 145-154.

16. Chim CS, Liang R \& Kwong YL (2002). Hypermethylation of gene promoters in hematological neoplasia. Hematological Oncology, 20: 167-176.
17. Takita J, Hayashi Y, Nakajima T, Adachi J, Tanaka T, Yamaguchi N, Ogawa Y, Hanada R, Yamamoto K \& Yokota J (1998). The p16 (CDKN2A) gene is involved in the growth of neuroblastoma cells and its expression is associated with prognosis of neuroblastoma patients. Oncogene, 17: 3137-3143.

18. Herman JG, Merlo A, Mao L, Mao L, Lapidus RG, Issa JPJ, Davidson NE, Sidransky D \& Baylin SB (1995). Inactivation of the CDKN2/p16/ MTS1 gene is frequently associated with aberrant DNA methylation in all common human cancers. Cancer Research, 55: 4525-4530.

19. Omura-Minamisawa M, Diccianni MB, Chang RC, Batova A, Bridgeman LJ, Schiff J, Cohn SL, London WB \& Yu AL (2001). P16/ $14 \mathrm{ARF}$ cell cycle regulatory pathways in primary neuroblastoma: p16 expression is associated with advanced stage disease. Clinical Cancer Research, 7: 3481-3490.

20. Giordani L, Iolascon A, Servedio V, Mazzocco K, Longo L \& Tonini GP (2002). Two regions of deletion in 9p22-24 in neuroblastoma are frequently observed in favorable tumors. Cancer Genetics and $\mathrm{Cy}$ togenetics, 135: 42-47.

21. Obana K, Yang HW, Piao HY et al. (2003). Aberrations of p16INK4A, p14ARF and p15INK4B genes in pediatric solid tumors. International Journal of Oncology, 23: 1151-1157. 